\title{
Primordial follicular assembly in humans - revisited
}

\author{
A. Maheshwari ${ }^{1}$ and P.A. Fowler ${ }^{2}$ \\ University of Aberdeen, Aberdeen Maternity Hospital; and University of Aberdeen Foresterhill, Aberdeen, UK.
}

Date submitted: 01.01.08. Date accepted: 05.03.08

\section{Summary}

Recent interest in the initial phases of ovarian follicular formation and development has lead to a number of publications in this area, most of which address the autocrine and paracrine factors involved in primordial follicle activation to primary follicle. Primordial follicle assembly (first step in follicle formation) determines the lifetime supply of primordial follicles and remains a poorly understood phenomenon. Despite a number of recent articles that are concentrating on immuno-histochemistry, basic steps in the process are not clear. Hence, we feel it is time to take a step back and see what is available in the literature and identify the gaps in which future research about primordial follicle assembly in humans needs to be directed.

Keywords: Fetal ovary, Folliculogenesis, Human, Ovary, Primordial follicle assembly

\section{Introduction}

In assisted conception, repeated attempts to overcome poor ovarian response by the use of increasing doses of gonadotropins (Klinkert et al., 2005) have failed to increase the number of oocytes retrieved. This situation has led to interest, on the part of researchers, to study the pregonadotropin-dependent phase of ovarian follicular development, beginning with the formation of the primordial follicle, which occurs in utero at the end of the second trimester. Primordial follicle assembly refers to the process by which primordial follicles are formed. The number of primordial follicles formed during the second trimester of fetal life determines the size of the primordial follicle pool for the reproductive lifetime of the resulting women, as the cells do not proliferate after formation (Kezele et al., 2005).

It is important to define precisely the timing and sequence of events involved in a normal primordial follicle assembly in order to: (a) define what is abnormal; (b) enable understanding of the potential

\footnotetext{
${ }^{1}$ All correspondence to: A. Maheshwari. University of Aberdeen, Aberdeen Maternity hospital, Aberdeen AB25 2ZL, Scotland, UK. Tel: +44 1224 554976. e-mail: Abha.maheshwari@abdn.ac.uk

${ }^{2}$ Centre for Reproductive Endocrinology and Medicine, Institute of Medical Sciences, University of Aberdeen, Aberdeen AB25 2ZD, Scotland, UK.
}

effects of exogenous agents and intrinsic chromosomal disorders on developing oocytes; (c) determine how various autocrine and paracrine markers affect the process of primordial follicle assembly; and (d) identify abnormalities that can lead potentially to premature ovarian failure and female infertility.

Despite being a critical process, primordial follicle assembly remains poorly understood. This fact is especially true in humans, in whom practical and ethical constraints limit the studies that can be performed. Most data, therefore, come from animal studies. The majority of the studies performed on humans have utilized ovaries from spontaneously aborted and chromosomally abnormal fetuses. This fact is unfortunate as such fetuses may not give a true representation of the normal process and may be a contributing factor in the various controversial statements regarding various steps involved in primordial follicle assembly (PFA).

It is clear that several autocrine and paracrine factors are involved in the process of primordial follicle assembly. Recent interest in the formation of primordial follicle has lead to number of articles about the various aspects of PFA especially the expression of various markers (SCF, c-kit, kit ligand, AMH, GDF-9, bcl-2, bax, etc.).

In this review, we have compiled what is already known and identified the limitations and gaps in understanding the process of primordial follicle assembly in humans. 


\section{Search strategy}

Medline and Embase was searched (1966-2007) using the keywords: primordial follicle, primordial follicle assembly, folliculogenesis, ovary, fetal ovaries, in utero, follicle development, oogenesis, human, c-kit, SCF (stem cell factor), Wnt, apoptosis, kit ligand, $\mathrm{AMH}$, GDF-9, bcl-2, bax, immunohistochemistry. Appropriate cross-references were manually searched as well. Only published literature was accessed.

\section{Sequence of events leading up to primordial follicle assembly}

Sex is determined genetically at conception. The presence of the testis-determining factor ( $Y$-chromosome gene Sry) guides gonadal differentiation to the formation of testes. Two testicular hormones, antiMüllerian hormone $(\mathrm{AMH})$ and testosterone are needed for normal masculinization and development of male internal and external genitalia. In contrast, female sexual development was thought to be spontaneous, without the need for ovarian hormonal activity (Voutilainen, 1992). More recent experiments on mice, however, have suggested that Wnt4 and follistatin have critical roles in female development. Wnt4 acts through follistatin to inhibit the formation of the cortical vessel. It also plays a role to maintain germ cell survival in the mouse ovary (Yao et al., 2004), although this remains to be proven for the human ovary. Follistatin was not expressed at all during 1421 weeks' gestation in human fetal ovary (Martins da Silva et al., 2004). To date, there is no published study that looks at the role of Wnt4 in human fetal ovary.

In humans the embryonic precursors of the gametes are known as primordial germ cells (PGC) (Donovan, 1998). Around 5 and 6 weeks of human development these cells are set aside to an extra-embryonic location, the yolk sac, and migrate by a combination of morphogenetic and self-propulsive movements along the hindgut to the genital ridge where they stay and increase in number (Stoop et al., 2005). Some of these cells fail to reach their destination and others end up in ectopic sites and die. Expression of SCF and c-kit has been documented in PGC, located in hindgut and dorsal mesentery, which suggests that they have a role in migration (Hoyer et al., 2005).

Once primordial germ cells reach the ovary they become spherical and are called oogonia (Table 1), which undergo extensive mitosis and increase in number. The oogonia then undergo meiosis to form oocytes. Some oocytes become surrounded by flattened granulosa cells (pregranulosa cells) to form primordial follicles, some of which later develop into primary follicles when the granulosa cells become cuboidal. In the primordial follicle oocytes reach the dictyate stage of prophase 1, at which point meiotic arrests occurs. They remain arrested in prophase I until recruited into the developing cohort of follicles. This process continues throughout life until the viable primordial follicle pool is exhausted. The growing follicles get lost through atresia, a process that involves apoptosis of both granulosa cells and the oocytes, unless rescued by follicle-stimulating hormone (FSH). This series of events is called follicle selection and happens only after puberty. The follicles that continue to grow under the control of FSH are eventually triggered to release their oocyte for fertilization by leutenizing hormone (LH). During ovulation, the long postponed final stages of meiosis in the oocyte are completed. The period of meiotic arrest can be as long as 40 years. Although follicles before the preantral follicle stage do not contain FSH receptors in the human ovary, experiments using hamster ovaries have suggested a role for FSH in primordial follicle assembly (Roy \& Albee, 2000).

In this review we will be covering events chronologically week-by-week, as they happen covering the period 6-26 weeks.

\section{Stages of events leading to primordial follicle formation}

\section{6-8 weeks}

Two authors have studied fetal human ovarian development between 6-10 weeks in detail (Kurilo, 1981; Satoh, 1991). The techniques for preparation of the cells (spread vs squash) and the population studied (after medical termination vs suction termination) are different, and, hence, there are inconsistencies in the findings documented. There is controversy in the literature as to when primordial germ cells become oogonia. Traditionally a primordial germ cell is called an oogonium when it reaches the ovary (Picton, 2001). However, the appearance of oogonia was noted for the first time at 9-10 weeks and only scattered primitive germ cells are present before this period (Gondos et al., 1986). There is an overlap in the light microscopic description of PGC and oogonia (Table 1). In an extensive study using spread cell preparations Kurilo (1981) was able to distinguish various stages and found that $8-10 \%$ of all cells at $6-8$ weeks' gestation were germ cells, the majority $(90 \%)$ of which were represented by oogonia ( $4 \%$ of those were seen dividing mitotically). Furthermore, $7-8 \%$ of germ cells were described as oocytes at preleptotene stage of chromosome condensation (Kurilo, 1981). 
Table 1 Description of various cells seen in fetal ovary.

\begin{tabular}{ll}
\hline Type of cell & Light microscopy description \\
\hline Primordial germ cell & $\begin{array}{l}\text { Large and irregular in contour } \\
\text { (Gondos } \text { et al.,1986) }\end{array}$
\end{tabular}

Electron microscopy description

Usually 10-15 $\mu \mathrm{m}$ in diameter and round in shape. Motta et al. (1997) described PGC as round only in the resting phase. In the active phase they are spindle shaped and about $30 \mu \mathrm{m}$ in length. The plasma membrane in the active phase forms protrusion and pseudopodia. Nuclei-large and round with evenly distributed chromatin and prominent nucleoli. There is infrequent mitotic activity but signs of degenerative changes are not seen (Konishi et al., 1986).The nucleoplasm is dense and homogeneous without evident aggregation of chromatin granules (Gondos et al., 1971). Cytoplasm contains circular mitochondria, tubular cristae and well developed ribosomes. There are scattered Golgi membranes and microfilaments. Glycogen particles and lipid droplets are commonly seen in the resting phase. The cytoplasm is abundant and complex. Numerous polyribosomes and mitochondria are present (Gondos et al., 1971)

Oogonia

Oocyte (NB Oocytes have been described in further detail depending on the stage of meiosis in Table 2)

Pregranulosa cell (somatic cell)

Interstitial cells
More rounded outline as compared with the primordial germ cell. A distinct increase in mitotic activity as compared with germ cell (Gondos et al., 1986) (De Pol et al., 1997) Spindle-shaped cells with small nuclei and dark cytoplasm (Konishi et al., 1986)
Oval nucleus with irregular outline

Smooth rounded contour and generally uniform in structure. NucleiSymmetrical and regular in outline. Cells contain a matrix of fibrillar and granular material that is dispersed randomly and possess a prominent nucleoli, which take the form of coarse irregular network of granular material. Cytoplasm - appears less dense than in PGC, due to a paucity of ribosomes and endoplasmic reticulum. Multiple small vesicles are present. Lipid droplets are rare. Mitochondria are globular with tubular cristae. Oogonia in mitosis can be recognized by globular mitochondria as compared with the elongated mitochondria of adjacent granulosa cells. (Gondos et al., 1971). Intercellular bridges (cylindrical rims of cytoplasm) connect adjacent oogonia. The bridges are first seen at 10 weeks and are commonly associated with dividing cells. Oogonia undergoing mitosis contains dense irregular masses of chromosome material, closely surrounded by chains of vesicular or double membranes (Gondos et al., 1971)

Oocytes are recognized by their band-like aggregations of nuclear granules, associated with the formation of synaptinemal complexes, which are characteristic of nuclei in meiotic prophase. Oocytes are considerably larger than the adjacent granulosa cells Adjacent oocytes are close to one another and are often connected by intercellular bridges (Gondos et al., 1971). Binucleate oocytes are occasionally seen. In addition, cytoplasm and mitochondria becomes more numerous and are disposed along the outer surface of cell membranes, often associated with microtubules. The Golgi apparatus is located near the nucleus, encircling the centriole.

Membrane-bound dense bodies can also be found in the cytoplasm (Motta et al., 1997). A peculiar feature of the human oocyte is the arrangement of mitochondria along the nuclear border. Such an arrangement has not been observed in other mammals. As compared with oogonia the cristae are more densely packed in mitochondria, consequently there is less intramitochondrial matrix. (Gondos et al., 1971)

Ellipsoid or spindle shaped, 5-10 $\mu \mathrm{m}$ long. Pregranulosa cells had ellipsoid nuclei with marginally condensed chromatin. The cytoplasm is electron dense compared with germ cells. This density is due to the presence of cytoplasm filaments, a few mitochondria with lamellar cristae, granular endoplasmic reticulum, and occasional lysosome-like granules are present. Cytoplasmic processes of the pregranulosa cells were elongated and they closely apposed the cell membrane of the germ cells or neighbouring pregranulosa cells. Desmosome-like junctions were seen both between pregranulosa cells and between pregranulosa cells and germ cells (Konishi et al., 1986)

There is abundance of smooth endoplasmic reticulum and the presence of large spherical mitochondria, prominent Golgi complexes and scattered

They are scattered cells in the medullary region with prominent eccentric nuclei and abundant deeply staining cytoplasm. These cells are 26-30 $\mu \mathrm{m}$ wide, i.e. considerably larger than adjacent stromal cells. They are identified by consistent location in the vicinity of blood vessels (Gondos \& Zamboni, 1973) dense bodies. The cytoplasm is filled with extensive formation of smooth endoplasmic reticulum, a characteristic feature of steroid-producing cells. Mitochondria contained prominent lamelliform cristae, some of which presented a tubular profile. Many of the mitochondria also contained osmiophilic inclusions of varying electron density, suggesting at least in some the presence of intramitochondrial lipid. Dense bodies, similar in appearance to microbodies (peroxisomes) described in Leydig cells of rodent testis, were distributed throughout the cytoplasm (Gondos \& Zamboni, 1973) 


\section{8-10 weeks}

Kurilo (1981) described a large increase in the number of oocytes that had reached the stage of chromosomal condensation and the active transition of oocytes to the next prochromosome decondensation stage. At this stage all of the germ cells were concentrated in the ovarian cortex and hence the cortex could be separated from the medulla. In addition, scattered degenerating cells were clearly visible. Bendsen et al. (2006) counted the number of somatic and germ cells in the human ovary between 8-11 weeks' gestation and demonstrated that the ratio between oogonia and somatic cells had a tendency to increase with age from 1:8 to 1:6 from 8-11 weeks. They also found that oogonia were evenly distributed within the cortical area.

\section{0-12 weeks}

In this phase the increase in mitotically dividing oogonia was uniformly reported by different authors (Kurilo, 1981; Gondos et al., 1986), with a process of active development of somatic cells within the ovary. At this stage germ cell production reaches its maximum rate. Oogonia constituted $50-60 \%$ of germ cells (Kurilo, 1981). Most of the dividing cells were temporarily arrested at metaphase with abnormal mitosis observed in $40 \%$ of dividing oogonia. Together with some somatic cells, the oogonia became arranged in interconnected cords or clusters delimited by a basement membrane and slender somatic cells (Gondos \& Zamboni, 1969; Wartenberg, 1982). This process has been very well described in the sheep (Fig. 1). Cells adjacent to oogonia are elongated, with irregular nuclei and cytoplasmic organization characteristic of granulosa cells. At 11-12 weeks, mitotic activity was seen in superficial layers of the ovarian cortex, whereas in deep layers germ cells entered various stages of meiotic prophase (Motta et al., 1997). At the same time, growth of stroma and capillaries from the medulla into the dense cortex began and a few cordlike nests of cells appeared in the inner portion of the cortex (Gondos et al., 1971).

\section{2-18 weeks}

The cortex and medulla have been described as clearly demarcated at 12 weeks of gestation, with cortex packed with germ and somatic cells. (Konishi et al., 1986). The increasing number of oocytes indicates an intensive period of meiotic events in the germ cells. Two markers of proliferation (Ki67 and histone 3) are expressed by cells engaged in mitosis in mid-trimester human fetal ovary (Fulton et al., 2005; Stoop et al., 2005). Hence, staining is seen in granulosa cells, interstitial cells and germ cells. The population used in both

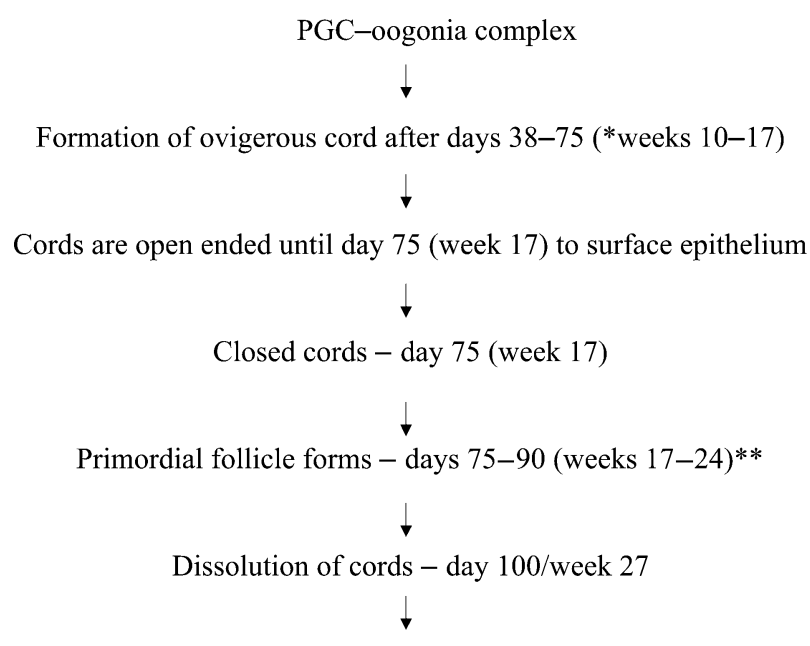

Maturation of primordial follicle and movement towards medulla

Figure 1 Conceptual model of ovigerous cords in sheep ovary (Sawyer et al., 2002). * weeks = approximate equivalent stage of human gestation; ** $75 \%$ of germ cells die. The sequential events leading to follicle formation take place entirely within ovigerous cords with first follicle forming at interface of cortex and medulla. The loss of germ cells within ovigerous cords is a means by which each surviving oocyte gains additional pregranulosa cells before follicle formation. Individual primordial follicle emerge completely enveloped within continuous basement membrane (follicle breakout).

studies were different (15.5-40 weeks' fetal ovaries after medical or spontaneous abortions and 14-19 weeks fetal ovaries after mid-trimester medical termination). Amongst germ cells both these markers were expressed by oogonia only, while oocytes engaged in primordial follicle assembly were Ki67 and histone 3 negative. Cells expressing both these markers, as a proportion of all germ cells, remained constant between 14-19 weeks despite marked increase in germ cells entering meiosis at this stage. When studying the expression of phospoH3, Fulton et al. (2005) found that the stromal cells and pregranulosa cells which were closely associated with oogonia before primordial follicle formation, showed limited mitotic activity when compared with the rest of somatic cells. At $11-15$ weeks only $50 \%$ of diplotene oocytes were surrounded by an incomplete layer of flattened granulosa cells. At 14-15 weeks, intensive passage of oocytes into diplotene stage and active follicular formation occurred (Kurilo, 1981). Oocyte entrance into the dictyone stage was characterized by increases in the nuclear and cytoplasmic vacuoles and by differentiation of the surrounding follicular cells. Medullary fibro-vascular tissue penetrates into the ovary and almost half of the cortex becomes divided. Mullerian inhibiting substance (MIS) has been shown to be expressed in the cytoplasm and the nucleus of the somatic/pregranulosa cells at around 13-15 
weeks of gestation. It was also noted that these MISpositive granulosa cells surrounded the germ cells (which did not express MIS) to form germ cell somatic cell complexes and later primordial follicle (Modi et al., 2006). The intensity of MIS expression was very low, when compared with corresponding gestation in testis, confirming the hormonal quiescence of ovary. Matrix metalloproteinases-1 (MMP-1) was found to be expressed in the cytoplasm of oocytes; stromal cells and surface epithelium, while MMP-2 and MMP-9 were present only in germ cell and surface epithelium during this gestational stage. Tissue inhibitor of matrix metalloproteinases-1 (TIMP-1) was localized to the cytoplasm of the oocytes and in the surface epithelium, TIMP-2 was present in germ cells and stroma, TIMP-3 in all three and TIMP-4 only in the cytoplasm of germ cell. All TIMPs and MMPs were localized in the vascular endothelium (Robinson et al., 2001b). These molecules were probably involved in the modelling of the extracellular matrix and in cell-matrix interaction.

\section{8-20 weeks}

In the ovaries at 18-20 weeks the cortex is composed of sex cords and clusters made up of both somatic and germ cells, oogonia and oocytes in the different stages of the first meiotic prophase. At the boundary with the medulla the primordial follicles begin to break away from clusters. Sex cords, clusters and follicles were surrounded and separated one from another by the mesenchymal tissue of the stroma (De Pol et al., 1997). Oocytes of different maturational stages were seen simultaneously. The mechanisms governing the individual maturational pace of oocytes are not known (Voutilainen, 1992). Most of the germ cells are surrounded by somatic cells. The ones that did not form an association (1-3\%) were found to express MIS to a similar intensity to that observed in the fetal testis. However, in this study (Modi et al., 2006) some of the germ cells negative for MIS were also not associated with somatic cells. Hence it is hard to detect the differences in the germ cells that do not engage in primordial follicle formation.

\section{0-22 weeks}

At 20 weeks the cords are well delineated from one another, because of the greatly increased growth of stromal connective tissue, which extends up to the periphery (Gondos et al., 1971; Konishi et al., 1986). In the ovaries of fetuses aged 19-22 weeks, the relative number of germ cells continues to decline. This is partially because of oocyte degeneration in the meiotic prophase and partly due to intense multiplication of ovary somatic cells. The number of oocytes at zygotene and pachytene and diplotene stage increased considerably. Most oocytes are contained in primordial follicles, which are localized not only on the cortexmedulla boundary, but also in the internal part of the cortex. The number of primary follicles is markedly increased $(8.2 \%)$, as compared with $18-20$ weeks. In some of these primary follicles, zona pellucida appears between the oocyte and the follicle layer (Kurilo, 1981).

\section{3-26 weeks}

There is further passage of oocytes into the diplotene stage while the number of oogonia steadily declines. Oogonia are visible either in a narrow subepithelial section of the cortex, or in germ cell 'islands' on the boundary between the cortex and medulla. There is an active transformation of the follicles from primordial to primary follicles $(26.2 \%)$ and some of the primary follicles already formed develop further into secondary follicles (Kurilo, 1981). GDF-9 has been found to play role in primordial follicle formation under experimental conditions in the hamster ovary (Wang \& Roy, 2004), but has not been found to be expressed in human ovary until the formation of primary follicle (Kaivooja et al., 2006).

\section{Timing of formation of the primordial follicle}

A primordial follicle typically has an oocyte in the first prophase of meiosis and a single layer of flattened granulosa cells. There is some uncertainty in the literature as to when the primordial follicle first appear. Various authors have favoured a number of critical periods including 15-16 weeks (Sforza et al., 2003), 18 weeks (Fulton et al., 2005) and 20-22 weeks (Abir et al., 2002). Their appearance is first visible in the innermost region of the cortex (Konishi et al., 1986).

\section{Interstitial cells}

The reported time of earliest appearance of interstitial cells is between 12 weeks (Gondos \& Hobel, 1973) to 15 weeks (Konishi et al., 1986), which is considerably later than Leydig cell appearance in testis (at around 8 weeks). The number of interstitial cells in the fetal ovary is far lower than the number of Leydig cell in the fetal testis. During the third and fourth months of gestation, dense confluent sheets of Leydig cells occupy major proportion of testicular tissue, while in the ovary, there are never more than a few scattered cells. These morphological differences are compatible to differences in the level of biochemical activity in the fetal ovary and testis (Gondos \& Hobel, 1973). Interstitial cells in the ovary have been identified as large round ellipsoid cells with round nuclei and abundant cytoplasm 
as they peak in number at 18 weeks, then decline between 21-31 weeks. As there is no fibrovascular penetration of the outer cortex there are no interstitial cells seen in that part of cortex (Konishi et al., 1986). Although the origin of the interstitial cells in the human ovary remains undetermined, the fibrovascular tissue dividing the cortex into cords consists of fibroblastlike cells. There are suggestions that the interstitial cells might differentiate from a fibroblast-like cell in the medulla (Konishi et al., 1986). Another interesting observation made with respect to interstitial cells is that they disappear in regions where primordial follicles are already formed (Konishi et al., 1986), suggesting active signalling by the primordial follicles in contrast to their endocrine inactivity.

\section{Onset of meiosis}

The initial distinctive changes in prenatal germ cell development in the ovary are: (1) the onset of meiosis; (2) meiotic arrest; and (3) granulosa cells surrounding the oocyte to form a primordial follicle. Once meiosis is initiated, the destiny of the oocyte is determined, and they can either degenerate or complete meiosis but cannot return to mitotic proliferation (Vaskivuo et al., 2001). Loss of pluripotency is being also suggested by declining expression of markers like OCT3/4 and placental/ germ-like cell alkaline phosphatase (PLAP) which are seen during oogenesis but not in germ cells engaged in folliculogenesis (Stoop et al., 2005). Expression of both the markers declined after 2425 weeks of gestation. Contradictory data exist with regard to the onset of meiosis, which has been reported to take place between 8-22 weeks of gestation (Gondos et al., 1986; Voutilainen 1992; Abir et al., 2002; Fulton et al., 2005; Stoop et al., 2005; Bendsen et al., 2006). The onset of meiosis is important in relation to the final number of oocytes. Awareness of the cellular changes immediately preceding and accompanying the initiation of meiosis is important since it is during this period that critical genetic events affecting subsequent developmental and reproductive capabilities occur. Around 11-12 weeks of gestation, the germ cells situated innermost in the cortex, enter prophase of the first meiotic division. This has been supported by immunohistochemistry, which has shown that the expression of histone 3, PLAP, OCT3/4 and Ki67 is restricted mainly to the cortical region (Fulton et al., 2005; Stoop et al., 2005). Gradually, meiosis spreads towards the periphery and by the time of birth most oocytes have entered the diplotene stage (Gondos et al,. 1986; Hoyer et al., 2005).

c-kit is a tyrosine kinase receptor for stem cell factor (SCF) and is also termed Kit-ligand (Kit-L), has been uniformly found to be uniformly expressed in the oocyte cell membrane (Robinson et al., 2001; Stoop et al., 2005). c-kit immuno-staining is restricted to the cell membrane of oogonia, whereas expression ceases with the onset of meiosis and resumes in growing preantral follicles. The mechanism governing the cessation and resumption of c-kit expression is not known (Hoyer et al., 2005). However, weak cytoplasmic staining has been documented in oocytes enclosed within primordial follicles (Robinson et al., 2001; Hoyer et al., 2005; Stoop et al., 2005). SCF itself is present in granulosa cells. c-Kit/SCF system has been implicated in survival of germ cells and activation of primordial follicles. SCF expression has been documented in somatic cells surrounding cords as well as in pregranulosa and granulosa cells of the primordial follicle (Hoyer et al., 2005). Neither c-kit nor SCF staining has been detected in meiotic oocytes, suggesting that they are not protected against apoptosis by the c-kit/SCF system.

Martins da Silva et al. (2004) have proposed a role for activin-A in the regulation of germ cell proliferation leading up to primordial follicle assembly. They demonstrated that activin-A was specifically expressed in germ cells and its expression increased with the size of germ cells, although, the oocytes in primordial follicles were negative. In contrast, the anti-apoptotic Bcl-2 family member, myeloid cell leukaemia-1 (Mcl-1), in addition to being expressed markedly in larger oogonia, continues to be expressed in oocytes within primordial follicles (Hatley et al., 2002). Activin-B was non-specifically expressed in germ cells as well as somatic cells of 14-21 weeks' ovaries (Martins da Silva et al., 2004). In contrast, while the germ cell marker VASA is being expressed in cytoplasm of all germ cells at all gestational stages, the intensity of VASA immunostaining is most marked in the primordial follicles (Stoop et al., 2005).

\section{Formation and regression of ovigerous cords}

There are suggestions that assembly or formation of primordial follicles requires individual oocytes to segregate and associate with squamous granulosa cells. Nests of associated oocytes might undergo random apoptosis of individual oocytes to derive isolated oocytes that then associate with precursor squamous granulosa cells (Skinner, 2005). Culture studies on neonatal rat ovaries suggests that high levels of progesterone in the media slow the process of primordial follicle assembly by inhibiting coordinated oocyte apoptosis, but it remains to be proven for the human fetal ovary (Keezele \& Skinner, 2003). Similarly it has been suggested that estradiol has a role in controlling initial size of primordial follicle pool in mice, but there is no evidence of human studies 
(Britt et al., 2004). Estradiol and progesterone in the maternal circulation of pregnant women reach 15-20 $\mathrm{nmol} / \mathrm{l}$ and $100-150 \mathrm{nmol} / 1$ respectively by 20 weeks of gestation (Fowler et al., 1998) and that steroid hormones readily cross the placenta to the fetus. Indeed, in the baboon, estrogen appears to be important for normal fetal follicular development (Pepe et al., 2006) and therefore this may be a fertile area for further study in the human.

The exact steps in formation and regression of ovigerous cords and in the subsequent formation of discrete primordial follicles have been defined in sheep and a conceptual model has been made (Fig. 1) (McNatty et al., 2000; Sawyer et al., 2002). The formation of primordial follicles involves separation of oocyte from the germ cell cords, the attachment of some somatic cells to the oocytes and formation of an intact basement membrane around this unit. Although species differences in the timing of specific events have been described, the overall chronology of events appears to be similar in many mammals However, this remains to be proven for primordial follicle assembly in humans. Extrapolating from the conceptual sheep model, the gestational age at which dissolution of the cords would be expected to occur is around 27 weeks (corresponding to the conceptual sheep model). Because of ethical constraints there is no availability of normal fetal ovary tissue around this gestation. Various studies have been done using spontaneously aborted fetuses, but there has been no mention of dissolution of cords. De Pol et al. (1997) mentions that, around 18-20 weeks, primordial follicles break away from nests but he only studied the gestation of between 18-20 weeks and a clear description of process of regression of cords is lacking.

Satoh (1991) has described the various types of cords in the human ovary (primary, primordial and folliculogenesis sex cords), which are present even at 6 weeks (primary sex cords), in contrast to the description by Gondos et al. (1971) where cords are first described at 10-12 weeks. None of the studies answer the question as to where the primordial follicle forms in relation to the cords and to the fate of the cords in human fetuses after formation of primordial follicle (Satoh, 1991). In addition, there is no mention of open or closed cords and hence there is no evidence, whether cords in human fetal ovary communicate with the surface epithelium. However, there are suggestions that the formation of the cords starts from inner portion of the cortex and extends to periphery.

\section{Origin of granulosa cells}

The origin of granulosa cells remains unclear. They may derive from the mesonephros, i.e. the intraovarian rete cells, and/or from the coelomic epithelium (Byskov, 1986) or from mesenchyme of the ovary (Pinkerton et al., 1961). In sheep they have been thought to arise from surface epithelium (Sawyer et al., 2002). In humans the mystery is still unresolved.

Expression of the survival/differentiation factor neurotropin $\mathrm{NT}_{4}$ expression is detected in cytoplasm of germ cells at 13-21 weeks of gestation. NT4 immunostaining is also observed in pregranulosa cells and granulosa cells surrounding the germ cell clusters and oocyte in primordial follicle. However no expression is seen in surface epithelium suggesting that granulosa cells do not originate from the surface epithelium. The other neurotropin investigated, nerve growth factor receptor (NGFR) was expressed only in stroma but not in the granulosa cells surrounding germ cells, ruling out stromal cells as origin of granulosa cells as well (Anderson et al., 2002).

\section{Changes in the gene expression}

Analysis of the rat ovarian transcriptome demonstrated that 148 genes were up-regulated and 50 genes were down-regulated when unassembled and primordial follicles were compared (Kezele et al., 2005). Similarly, the gene, factor in germline alpha (FIGLA), is expressed specifically in mouse germs cells and is required for the germ cells to survive and form primordial follicles. Human FIGLA protein increases 40 -fold times at the time of primordial follicle formation in the human fetal ovary and is thought to be important for germ cell survival required for primordial follicle formation (Bayne et al., 2004). No large scale transcriptome data are available for human ovaries yet, however. Only one study (Serafica et al., 2005) has looked at the gene resource of assembled primordial follicle, but this was based on adult ovaries removed from trans-sexuals during surgery.

\section{Mechanisms leading to a decrease in germ cell numbers}

The germ cell population peaks around the fifth month of fetal life at around 5-7 $\times 10^{6}$. Subsequently, germ cells decrease sharply and the number drops to about $7 \times 10^{5}$ oocytes, contained in follicles at birth (Baker, 1963). The exact mechanism that induces the decrease in germ cells (oogonia and oocyte) throughout the gestation is unknown. There is evidence that apoptosis is the major mechanism of germ cell loss (De Pol et al., 1997). This theory has been supported by immunohistochemistry using TUNEL (Abir et al., 2002; Modi et al., 2003), although TUNEL alone may 
underestimate the incidence of apoptosis as DNA degradation is the late event in the sequence of events during cell death (Hartley et al., 2002).

One of the remarkable features of germ cell apoptosis in the human fetal ovary is the preservation of cytoplasmic organelles (De Pol et al., 1997). Irregularities in the outline of the nucleus, followed by thickened chromatin and a decrease in size or breaking into fragments can be recognized, but cytoplasmic alterations do not appear to be particularly evident with light microscopy (De Pol et al., 1997). During fetal life apoptosis in the ovary is localized to oocytes, whereas, in adult life, it is detected in the granulosa cells of growing follicles. This fact has been attributed to the non-proliferative state of most of granulosa cells in the first two trimesters (Abir et al., 2002; Hussein 2005). Apoptosis of pregranulosa cells and granulosa cells (Vaskivou et al., 2001; Modi et al., 2003) have also been reported. Kim \& Tilly (2004) have suggested that although atresia can occur at any stage of the follicular development, in primordial, primary and small preantral follicles apoptosis of the oocyte itself initiates atresia. This situation contrasts with the later stages in which granulosa cells are the underlying cause of atresia.

There is a wide variation in the timing of maximal apoptosis described in literature. Germ cell degeneration was reported to be negligible at 11-12 weeks by Kurilo (1981), despite the use of electron microscopy. Vaskivuo et al. (2001) noted an occasional apoptotic oocyte before 13 weeks, with a peak in the number of apoptotic oocytes between 13 and 14 weeks, followed by a decline in last quarter of fetal life. Hussein et al. (2005) described apoptosis as highest between weeks 14 and 28 and then decreases thereafter. Abir et al. (2002) showed no apoptosis before 23 weeks and a peak at 27 weeks, however. The gestation age range used by Abir et al. (2002) was 19-33 weeks and the authors documented that the apoptotic rates are too low to explain the extensive germ cell loss throughout the human gestation. This finding may suggests that a peak of apoptosis is before 19 weeks, which was missed in this study (Abir et al., 2002) due to the age range of fetuses used. Moreover, data from this study included fetuses that had been aborted more than 24 hours after feticide or long after intrauterine death and it can be difficult to distinguish between apoptosis and necrosis. It has been suggested by Gumienny et al. (1999) that apoptotic cells disappear rapidly, which might explain the variation in different studies, on top of the compound error inherent in comparing the data using different measures of apoptosis.

Germ cell loss has been described as occurring in three waves with numerically the most important wave coinciding with the appearance of primordial follicles (Baker, 1963). In the sheep, $75 \%$ of germ cells in the ovary are lost between gestation days 75 and 90 (corresponding to 17-24 weeks in human), when primordial follicle formation is occurring. Similar findings have been seen in human ovaries, although there is a rather more gradual increase in apoptosis (Fulton et al., 2005) rather than dramatic increase as seen in mouse (Pepling \& Spradling, 2001), has been described. Culture studies suggest a role of Trk B receptors and their ligands in the regulation of germ cell survival at the oogonial and primordial follicle stage (Spears et al., 2003).

Primordial follicles are formed when oocytes become individually surrounded by somatic cells (Hirshfield, 1991) and it is this interaction that has been identified as the event that determines oocyte survival and protection against apoptosis. c-Kit has been postulated to play a role in germ cell survival, possibly by upregulating Mcl-1 (Hartley et al., 2002).

Sometimes it is difficult to distinguish degenerative and possible early meiotic changes because of prominent chromatin condensation (Gondos et al., 1986). Using electron microscopy, the presence of extensive cytoplasmic vesiculation indicates degenerative rather than early meiotic change (Tables 1 and 2).

Mcl-1 and Bcl-2 have been diagnosed as antiapoptotic factors whereas Bax and BAD are proapoptotic. In the human fetal ovary, Mcl-1 is expressed exclusively by germ cells (Hartley et al., 2002), Bcl- 2 by somatic cells and Bax and BAD were expressed by somatic cells as well as well as germ cells. Most intense immunostaining with Bcl-1 was seen in oocytes inside the primordial follicles suggesting that they are protected. This finding has been supported by Fulton et al. (2005) who showed that apoptosis increases immediately before primordial follicle formation.

From animal studies, pro-apoptotic caspases (-2 and -3 ) have been implicated in the pathways of germ cell apoptosis. Their expression has been detected in the human fetal ovary (cleaved caspase-3) between 14-19 weeks, a time leading to primordial follicle formation. However, in the human fetal ovary caspases were only detected in germ cells that were not part of primordial follicles, further confirming the protective environment of the primordial follicle for the oocyte (Fulton et al., 2005).

Vasukivuo et al. (2001) postulated that GATA-4 might play a protective role for granulosa cells. GATA-4 protein was mainly localized in granulosa cells and to a lesser extent in pre-granulosa cells from 13-14 weeks onwards. No expression was seen in germ cells. Culture studies in 13-16 weeks' human ovaries suggest that Trk signalling may play a role in oogonial survival (Spears et al., 2003). 
Table 2 Structure of the oocyte at various stages of meiosis (as described by Baker \& Franchi, 1967).

\begin{tabular}{|c|c|c|c|c|}
\hline Stage & Nuclei & Nucleolus & Cytoplasm & Size \\
\hline Preleptotene & Irregularly shaped & $\begin{array}{l}\text { Present, though smaller, } \\
\text { denser and more vacuolated } \\
\text { as compared to oogonia }\end{array}$ & Similar to that of oogonia & \\
\hline Leptotene & $\begin{array}{l}\text { Contains numerous fine } \\
\text { electron dense threads ( } 450 \AA \\
\text { thick). They tend to be } \\
\text { oriented in one direction. Each } \\
\text { thread is enclosed by a sheath } \\
\text { of fibrillar material. The outer } \\
\text { limit of sheath is diffuse since } \\
\text { the fibrils merge with those in } \\
\text { the surrounding nuclear } \\
\text { matrix }\end{array}$ & $\begin{array}{l}\text { One or more nucleolar bodies } \\
\text { are observed as well as } \\
\text { occasional large nucleolus, } \\
\text { which is more homogenous as } \\
\text { compared to previous stages }\end{array}$ & $\begin{array}{l}\text { Similar to that of oogonia. Prominent } \\
\text { pores are evident in some regions of } \\
\text { the nuclear envelope, and in other } \\
\text { areas there are small areas over } \\
\text { which the two membranes are more } \\
\text { than usually separated. } \\
\text { Mitochondria are closely associated } \\
\text { with the nuclear envelope }\end{array}$ & \\
\hline Zygotene & $\begin{array}{l}\text { The threads in adjacent } \\
\text { sections tend to be polarized. } \\
\text { There are signs of pairing } \\
\text { between the threads. } \\
\text { Particularly near the nuclear } \\
\text { envelope. Many short } \\
\text { segments of unpaired threads } \\
\text { and occasionally of tripartite } \\
\text { ribbons are also seen in the } \\
\text { nucleus }\end{array}$ & & Similar to earlier stages & \\
\hline Pachytene & $\begin{array}{l}\text { Nuclei possess thick } \\
\text { chromosomes, which mostly } \\
\text { lack the polarized } \\
\text { configuration seen at the } \\
\text { earlier stages. Many sections } \\
\text { of tripartite ribbons are seen } \\
\text { although occasionally } \\
\text { unpaired threads are seen. } \\
\text { Variation in appearances of } \\
\text { ribbon is due to their helical } \\
\text { twisting and undulation in } \\
\text { and out of plane of the section. } \\
\text { In some nuclei ribbons are } \\
\text { further complicated by } \\
\text { longitudinal subdivision of the } \\
\text { lateral arms }\end{array}$ & & $\begin{array}{l}\text { More complex cytoplasm. Spherical } \\
\text { and ovoid mitochondria are plentiful } \\
\text { and their parallel cristae are well } \\
\text { developed. While most } \\
\text { mitochondria are scattered randomly } \\
\text { in cytoplasm, those that remain close } \\
\text { to nucleus are more flattened, with } \\
\text { their long axis lying parallel to the } \\
\text { nuclear envelope. Vesicles of } \\
\text { endoplasmic reticulum are more } \\
\text { abundant and vary considerable in } \\
\text { size. A few ribosomes are seen in } \\
\text { association with them. The Golgi } \\
\text { apparatus is prominent at one pole } \\
\text { of the nucleus and contains groups } \\
\text { of distended cisternae and numerous } \\
\text { small vesicles. Occasional organelles } \\
\text { resembling multivesicular bodies are } \\
\text { also observed }\end{array}$ & $\begin{array}{l}\text { Generally larger } \\
\text { oocytes than previous } \\
\text { stages }\end{array}$ \\
\hline Diplotene & $\begin{array}{l}\text { Contains unpaired electron } \\
\text { dense threads, the continuity } \\
\text { of which is interrupted at } \\
\text { irregular intervals, } \\
\text { presumably due to undulation } \\
\text { in and out of the plane of } \\
\text { section. The whole thread is } \\
\text { closely invested by a sheath } \\
\text { similar in composition to that } \\
\text { observed in pachytene }\end{array}$ & $\begin{array}{l}\text { The nucleoli are large and } \\
\text { uniformly granular but may } \\
\text { contain clear, vacuole like } \\
\text { areas. Smaller nucleoli are } \\
\text { large and are uniformly } \\
\text { granular but may contain } \\
\text { clear, vacuolated areas. The } \\
\text { nuclear envelope bears well } \\
\text { developed pores but at some } \\
\text { points the membranes are } \\
\text { more widely separated to } \\
\text { form pockets, which often } \\
\text { contain vesicular profiles }\end{array}$ & $\begin{array}{l}\text { Similar to that at pachytene except } \\
\text { for the association of mitochondria } \\
\text { with the nuclear membrane is much } \\
\text { less marked. In the larger primordial } \\
\text { follicles, mitochondria tend to } \\
\text { congregate in one half of oocyte, are } \\
\text { less regular in outline, and their } \\
\text { cristae may project radially into the } \\
\text { lumen of the organelle. The Golgi } \\
\text { apparatus contains fewer distended } \\
\text { cisternae; instead short tubular } \\
\text { profiles are present. The } \\
\text { endoplasmic reticulum is } \\
\text { represented by small vesicles similar } \\
\text { to those in the nuclear pockets and } \\
\text { may be continuous with them }\end{array}$ & $\begin{array}{l}\text { Larger than those at } \\
\text { earlier stages of } \\
\text { meiotic prophase and } \\
\text { may be partly or } \\
\text { wholly surrounded } \\
\text { by flattened follicular } \\
\text { cells }\end{array}$ \\
\hline
\end{tabular}




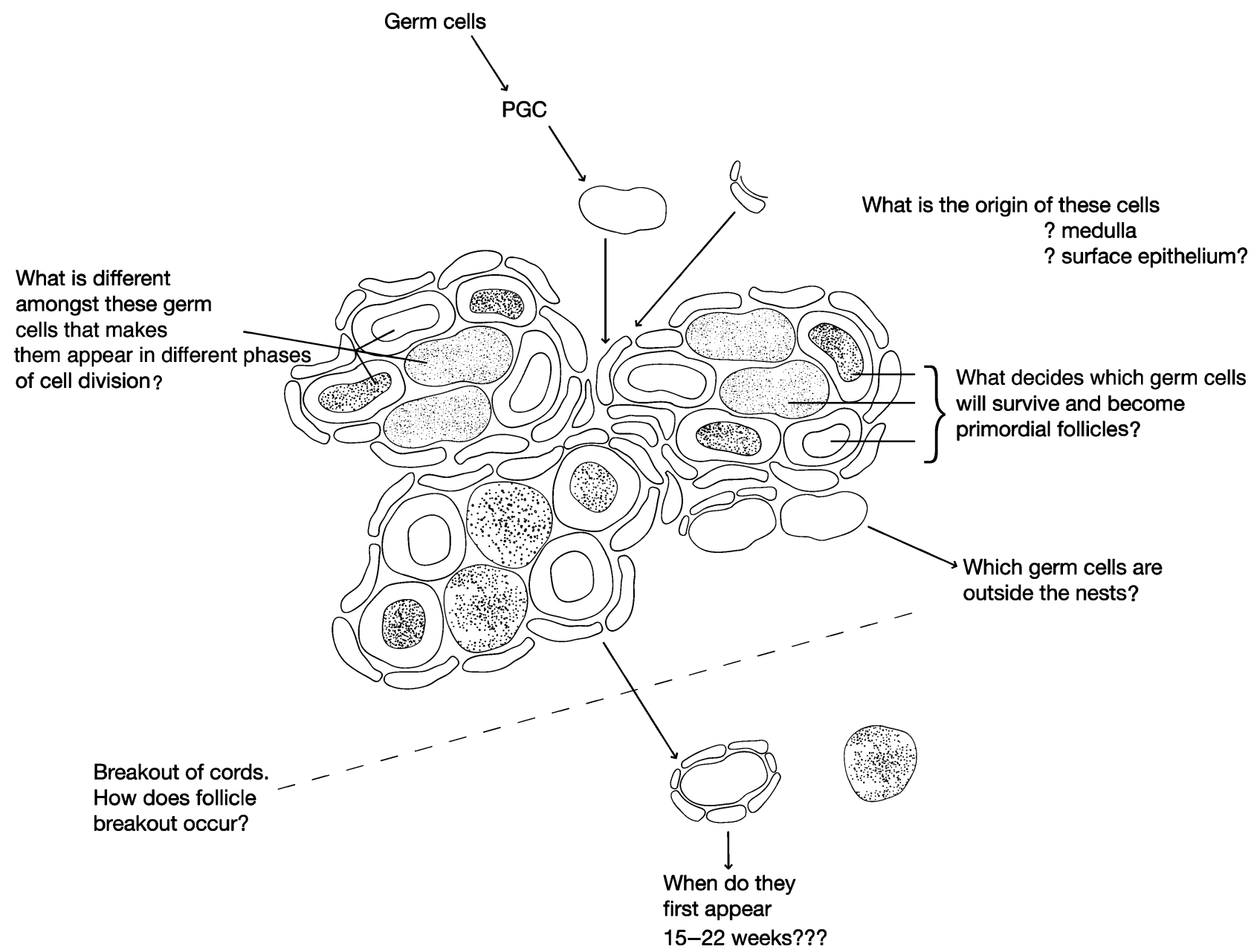

Figure 2 Primordial follicle assembly. A mystery!

\section{Primordial follicle assembly remains a mystery!!}

The reason for using immunohistochemical methods is to localise and elucidate the various cell-cell interactions that are involved between different cells. Hence it is essential to identify various cell types accurately. As shown in Tables 1 and 2 the light microscopy description of cells at various stages shows overlap. There have been attempts to find markers that are specific to various cell types and developmental stages, but those found so far are quite non-specific. For instance, several markers for granulosa cells will stain other somatic cells, which makes it difficult to differentiate between these cell types and hence trace their origin.

Despite the fact there is a body of literature with respect to the human ovary, a few pieces are still missing from the puzzle of primordial follicle assembly. There are important unanswered questions as shown in Fig. 2:
- When do primordial cells become oogonia?

- Why are some oocytes excluded from primordial follicles?

- When does primordial follicle assembly start?

- When does meiosis starts?

- What happens to the cords when primordial follicles are fully formed?

- What is the origin of the granulosa cells?

- At what stage is germ cell apoptosis maximum?

Hence more research is required in this area. As most of the recent studies are being performed in fetuses less than 21-22 weeks' (before the age of viability), it will still be difficult to follow the processes that happens after this gestation. However, it will be beneficial to standardize the processing and staining techniques as well as the description of each kind of cell as the resource of human ovary is limited. This approach will help to combine the studies to unravel the mystery of primordial follicle assembly, which itself will shed light on factors determining woman's reproductive capacity. 


\section{References}

Abir, R., Orvieto, R., Dicker, D., Zukerman, ?., Barnett, M. \& Fisch, B. (2002). Preliminary studies on apoptosis in human fetal ovaries. Fertil. Steril. 78, 259-64.

Abir, R., Fisch, B., Jin, S., Barnnet, M., Kesler-Icekson, G. \& Ao, A. (2004). Expression of stem cell factor and its receptor in human fetal and adult ovaries. Fertil. Steril. 82(Suppl 3) 1235-43.

Anderson, R.A., Robinson, L.L., Brooks, J., Spears, N. (2002). Neurotropins and their receptors are expressed in the human fetal ovary. J. Clin. Endocrinol. Metab. 87, 890-7.

Baker, T.G. (1963). A quantitative and cytologic study of germ cells in human ovaries. Proc. R. Soc. Lond. B Biol. Sci. 158, 417-33.

Baker, T.G. \& Franchi, L.L. (1967). The fine structure of oogonia and oocytes in human ovaries. J. Cell. Sci. 2, 213-24.

Bayne, R.A.L., Martins da Silva, S.J. \& Anderson, R.A. (2004). Increased expression of the FIGLA transcription factor is associated with primordial follicle formation in the human fetal ovary. Mol. Hum. Reprod. 10, 373-81.

Bendsen, E., Byskov, A.G., Andersen, C.Y. \& Westergaard, L.G. (2006). Number of germ cells and somatic cells in human fetal ovaries during the first weeks after sex differentiation. Hum. Reprod. 21, 30-5.

Britt, K.L., Saunders, P.K., McPherson, S.J., Misso, M.L., Simpson, E.R. \& Findlay, J.K. (2004). Estrogen actions on follicle formation and early follicle development. Biol. Reprod. 71, 1712-23.

Byskov, A.G. (1986). Differentiation of mammalian embryonic gonad. Physiol. Rev. 66, 71-117.

De Pol, A., Vaccina, F., Forabosco, A., Cavazzuti, E. \& Marzona, L. (1997). Apoptosis of germ cells during human prenatal oogenesis. Hum. Reprod. 12, 2235-41.

Donovan, P.J. (1998). The germ cell - the mother of all stem cells. Int. J. Dev. Biol. 42, 1043-50.

Fowler, P.A., Evans, L.W., Groome, N.P., Templeton, A. \& Knight, P.G. (1998). Pro-alphaC and follistatin during pregnancy - a longitudinal study of maternal serum inhibin-A, inhibin-B, activin-A, activin-AB. Hum. Reprod. 13, 3530-6.

Fulton, N., Martins da Silva, S.J., Bayne, R.A.L. \& Anderson, R.A. (2005). Germ cell proliferation and apoptosis in the developing human ovary. Endocrinol. Metab. 90, 466470.

Gondos, B. \& Hobel, C.J. (1973). Interstitial cells in the human fetal ovary. Endocrinology 93, 736-9.

Gondos, B. \& Zamboni, L. (1969). Ovarian development: the functional importance of germ cell interconnections. Fertil. Steril. 20, 176-89.

Gondos, B., Bhiraleus, P. \& Hobel, C.J. (1971). Ultrastructural observations on germ cells in human fetal ovaries. Am. J. Obstet. Gynecol. 110, 644-52.

Gondos, B., Westergaard, L. \& Byskov, A.G. (1986). Initiation of oogenesis in the human fetal ovary: ultrastructural and squash preparation study. Am. J. Obstet. Gynecol. 155, 18995.

Gumienny, T.L, Lambie, E., Hartwieg, E., Horvitz, H.R. \& Hengartner, M.O. (1999). Genetic control of programmed cell death in the Caenorhabditis elegans hermaphrodite germline. Development 126, 1011-22.
Hartley, P.S, Bayne, R.A.L, Robinson, L.L.L, Fulton, N. \& Anderson, R.A. (2002). Developmental changes in expression of myeloid cell leukemia-1 in human germ cells during oogenesis and early folliculogenesis. J. Clin. Endocrinol. Metab. 87, 3417-27.

Hirshfield, A.N. (1991). Development of follicles in the mammalian ovary. Int. Rev. Cytol. 124, 43-101.

Hoyer, P.E, Byskov, A.G. \& Mollgard, K. (2005). Stem cell factor and c-Kit in human primordial germ cells and fetal ovaries. Mol. Cell. Endocrinol. 234, 1-10.

Hussein, M.R. (2005). Apoptosis in the ovary: molecular mechanisms. Hum. Reprod. Update 11, 162-78.

Kaivooja, N., Jeffery, L.A., Ritvos, O. \& Mottershead, D. (2006). SMAD signalling in the ovary. Reprod. Biol. Endocrinol. 4, 21-33.

Kezele, P. \& Skinner, M.K. (2003). Regulation of primordial follicle assembly and development by estrogens and progesterones: endocrine model of follicle assembly. Endocrinology 144, 3329-37.

Kezele, P.R, Ague, J.M., Nilsson, E. \& Skinner, M.K. (2005). Alterations in ovarian transcriptome during primordial follicle assembly and development. Biol. Reprod. 72, 24155.

Kim, M.R. \& Tilly, J.L. (2004). Current concepts in Bcl-2 family member regulation of female germ cell development and survival. Biochimica et Biophysica Acta 1644, 205-10.

Klinkert, E.R, Broekmans, F.J, Looman, C.W., Habbema, J.D. \& te Velde, E.R. (2005). Expected poor responders on the basis of an antral follicle count do not benefit from a higher starting dose of gonadotrophins in IVF treatment: a randomized controlled trial. Hum. Reprod. 20, 611-5.

Konishi, I., Fujii, S., Okamura, H., Parmley, T. \& Mori, T. (1986). Development of interstitial cells and ovigerous cords in the human fetal ovary: an ultra-structural study. J. Anat. 148, 121-35.

Kurilo, L.F. (1981). Oogenesis in antenatal development in man. Hum. Genet. 57, 86-92.

Martins da Silva, S.J., Bayne, R.A.L., Cambray, N., Hartley, P.S., McNeilly, A.S. \& Anderson, R.A. (2004). Expression of activin subunits and receptors in the developing human ovary: activin A promotes germ cell survival and proliferation before primordial follicle formation. Develop. Biol. 266, 334-45.

McNatty, K.P., Fidler, A.E., Juengel, J.L., Quirke, L.D., Smith, P.R., Heath, D.A., Lundy, T., O'Connell, A. \& Tisdall, D.J. (2000). Growth and paracrine factors regulating follicular formation and cellular function. Mol. Cell. Endocrinol. 163, 11-20.

Modi, D.N., Sane, S. \& Bhartiya, D. (2003). Accelerated germ cell apoptosis in sex chromosome aneuploid fetal human gonads. Mol. Hum. Reprod. 9, 219-25.

Modi, D., Bhartiya, D. \& Puri, C. (2006). Developmental expression and cellular distribution of Mullerian inhibiting substance in the primate ovary. Reproduction 132, 443-53.

Motta, P.M., Nottola, S.A. \& Makabe, S. (1997). Natural history of the female germ cell from its origin to full maturation through prenatal ovarian development. Euro. J. Obstet. Gynecol. Reprod. Biol. 75, 5-10.

Pepe, G.J., Billiar, R.B. \& Albrecht, E.D. (2006). Regulation of baboon fetal ovarian folliculogenesis by estrogen. Mol. Cell. Endocrinol. 247, 41-6. 
Pepling, M.E. \& Spradling, A.C. (2001). Mouse ovarian germ cell cysts undergo programmed breakdown to form primordial follicles. Develop. Biol. 234, 339-51.

Picton, H.M. (2001). Activation of follicle development: the primordial follicle. Theriogenology 55, 1193-210.

Pinkerton, J.H.M, McKay, D.G., Adams, E.C. \& Hertig, A.T. (1961). Development of the human ovary-a study using histochemical technics. Obstet. Gynecol. 18, 15281.

Robinson, L.L.L., Gaskell, T.L., Saunders, T.K. \& Anderson, R.A. (2001a). Germ cell specific expression of c-kit in human fetal gonad. Mol. Hum. Reprod. 7, 845-52.

Robinson, L.L.L., Sznadjer, N.A., Riley, S.C. \& Anderson, R.A. (2001b). Matrix metalloproteinases and tissue inhibitors of metalloproteinases in human fetal testis and ovary. Mol. Hum. Reprod. 7, 641-8.

Roy, S.K. \& Albee, L. (2000). Requirement for folliclestimulating hormone action in the formation of primordial follicles during perinatal ovarian development in the hamster. Endocrinology 141, 4449-56.

Satoh, M. (1991). Histogenesis and organogenesis of the gonad in human embryos. J. Anat. 177, 85-107.

Sawyer, H.R., Smith, P., Heath, D.A., Juengel, J.L., Wakefield, S.J. and McNatty, K.P. (2002). Formation of ovarian follicles during fetal development in sheep. Biol. Reprod. 66, 113450.

Serafica, M.D., Goto, T. \& Trounson, A.O. (2005). Transcripts from a human primordial follicle cDNA library. Hum. Reprod. 20, 2074-91.

Sforza, C., Vizzotto, L., Ferrario, V.F. \& Forabosco, A. (2003). Position of follicles in normal human ovary during definitive histogenesis. Early Hum. Develop. 74, 27-35.
Skinner, M.K. (2005). Regulation of primordial follicle assembly and development. Hum. Reprod. Update 11, 46171.

Spears, N., Molinek, M.D., Robinson, L.L., Fulton, N., Cameron, H., Shimoda, K., Telfer, E.E., Anderson, R.A. \& Price, D.J. (2003). The role of neurotrophin receptors in female germ-cell survival in mouse and human. Development 130, 5481-91.

Stoop, H., Honecker, F., Cools, M., de Krijger, R., Bokemeyer, C. \& Looijenga, L.H.J. (2005). Differentation and development of human female germ cells during prenatal gonadogenesis: an immunohistochemical study. Hum. Reprod. 20, 1466-76.

Vaskivuo, T.E., Anttonen, M., Herva, R., Billig, H., Dorland, M., te Velde, E.R., Stenback, F., Heikinheimo, M. \& Tapanainen, J.S. (2001). Survival of human ovarian follicles from fetal to adult life: apoptosis, apoptosis related proteins, and transcription factor GATA-4. J. Clin. Endocrinol. Metab. 86, 3421-9.

Voutilainen, R. (1992). Differentiation of fetal gonad. Horm. Res. 38 (Suppl 2), 66-71.

Wang, J. \& Roy, S.K. (2004). Growth differentiation factor9 and stem cell factor promote primordial follicle formation in the hamster: modulation by folliclestimulating hormone. Biol. Reprod. 70, 577-85.

Wartenberg, H. (1982). Development of the early human ovary and role of the mesonephros in the differentiation of the cortex. Anat. Embryol. 165, 253-80.

Yao, H.H.C, Matzuk, M.M., Jorgez, C.J., Menke, D.B., Page, D.C., Swain, A. \& Capel, B. (2004). Follistatin operates downstream of Wnt4 in mammalian ovary organogenesis. Dev. Dynamics 230, 210-5. 